\title{
USE OF THE UNITED THEORY OF ACCEPTANCE AND USE OF TECHNOLOGY MODEL TO STUDY INFORMATION COMMUNICATION TECHNOLOGY- ADOPTION IN FIVE SAUDI ARABIAN PRIVATE HOSPITALS
}

\author{
Amnah $A B^{1}$, Bulgiba $A^{2,}$ Omar $R^{3}$ \\ 1 University of Malaya, Kuala Lumpur \\ 2 Julius Centre University of Malaya, Department of Social and Preventive Medicine, University of Malaya, Kuala Lumpur \\ 3 University Technology Malaysia, Kuala Lumpur
}

\author{
Correspondence: \\ Awang Bulgiba \\ Julius Centre University of Malaya, \\ Department of Social \& Preventive Medicine, \\ Faculty of Medicine, University of Malaya, \\ 50603 Kuala Lumpur, Malaysia. \\ Email: awang@ummc.edu.my
}

\begin{abstract}
We conducted a multi-institutional case study to identify the issues associated with the adoption of information and communication technology (ICT) in five private care hospitals in the Kingdom of Saudi Arabia. We conducted interviews with 37 respondents primarily comprising IT professionals.

We found that there were three determinants of behavioural intentions in this case study: organisation objectives, facilitating conditions and social influence where there are no effects of performance expectancy or effort expectancy. In all five cases, none of the moderators (age, gender, experience and voluntariness) in the original united theory of acceptance and use of technology model were considered critically important by IT professionals. In the present paper, all qualitative elements such as themes, patterns and overarching in the data were analysed to reach a conclusion. In addition, the various perspectives of using ICT are discussed.
\end{abstract}

Keywords: Effort Expectancy, Information and Communication Technology (ICT), Performance Expectancy, Social Influence, Turnover and Talent Acquisition, Vendor Credibility.

\section{Introduction}

Information and communication technology (ICT) is viewed as an effective tool to improve the quality of health services. A number of studies (1-3) explain how adoption of ICT in healthcare organisations, particularly hospitals, successfully supports solutions for improved services of the organisation. Nevertheless, many of these studies were conducted in non-Arab settings with economies that can be described as matured. Thus, some of the existing and contemporary challenges that could lead to a better understanding of ICT adoption in private hospitals in developing economies may not be sufficiently covered in the literature.

Developing countries such as India and China have also made significant contributions to the development of this technology $(4,5)$. Many developing countries have started implementing measures to improve their national information infrastructure and create an environment conducive to ICT growth as a tool to advance human development (6). In Saudi Arabia, expenditure on IT services witnessed an annual growth rate of $45.7 \%$, i.e. up to 7.9 billion riyals, in 2012 (6). However, Altuwaijiri (7) observed that the Saudi healthcare sector has not yet attained significant levels of advancement in the field of ICT; in fact, its use had created technology gaps between clinical professionals and data managers. The aim of this study was to explore the adoption of ICT in five private hospitals in Saudi Arabia according to the unified theory of acceptance and use of technology (UTAUT) model. Such phenomenon of technology adoption in various contexts and settings has been examined and explored through 
different theories of technology adoption such as the theory of reasoned action (8), technology acceptance model (9), theory of planned behaviour (9), diffusion of innovation theory (10) and UTAUT (11).

The Unified Theory of Acceptance and Use of Technology (UTAUT) model (11) was a result of integrating eight theoretical models (Figure 1). It has been successfully employed in many technology adoption studies (12). UTAUT has been tested in different countries such as the USA (13), study used UTAUT to examine Hospital Information Technology (HIT) adoption in a small medical office. The results of the study reveal that a major factor affecting HIT adoption in a specialty practice was the physician's need to have regulations to protect the privacy and increase the security of patient data. UTAUT has been used in different types of healthcare organisations $(14,15)$. According to Ivanov (14), individual attitudes and habits are significant factors affecting the establishment of new technology in healthcare practices (14).

\section{Methods}

\section{Study design}

In order to understand the crux of the issues of ICT adoption in Saudi, we conducted a multi-institutional case study. The case study method was chosen on the basis of the aims of this study, which were to discover qualitative elements such as themes, patterns in five private hospitals, the Specialized Medical Center Hospital, the Sulaiman Al-Habib Medical Group, the Al-Muwasat Hospital, the Saudi German Hospitals Group and Kingdom Hospital. The five private hospitals were categorised according to the length of time they have been in operation. Based on the year in which the hospital was established, the hospital was considered either newly established/young or experienced/mature.

These hospitals were chosen for this study because they are the biggest private hospitals in Saudi Arabia. For this study, hospitals established after the year 2000 were recognised as newly established or young. Conversely, the hospitals founded and established before the year 2000 were classified as experienced or mature hospitals.

The newly established hospital group comprised the Kingdom Hospital, Specialized Medical Center Hospital and Sulaiman Al-Habib Medical Group, whereas experienced and mature hospitals group comprised the Al-Muwasat Hospital and Saudi German Hospitals Group. (Table 1).

\section{Data collection}

This study was conducted using qualitative research methods, specifically the interview method. The interview method enabled the researchers to understand issues in a deep manner that could not have been possibly achieved using quantitative measures. Henceforth, the researchers made enquiries and elicited opinions on issues and factors influencing the adoption of ICT in these hospitals. This approach helped the researchers develop in-depth understanding on unique social and behavioural patterns as well as specific contextual elements within the organisational settings that influence respective ICT adoptions. The respondents were asked to answer three questions: How mature are the situational and interactional workflow conditions in your hospital? What are the factors affecting the adoption of information and communication technology in your hospital? What aspects or challenges will encourage or discourage from achieving full information and communication technology utilisation in healthcare?

The required data were gathered by interviewing 37 respondents who were selected according to their experiences, knowledge and educational attainment. The participants comprised IT personnel and administrative staff of these hospitals. Each interviewee was briefed on the information concerning the goals of the study and the purpose of conducting the interviews.

All interviews were conducted in Arabic. Each interview session lasted from 50 minutes to one hour. With the permission of the interviewees, most sessions were audiotaped. The recorded interviews were then transcribed and analysed to determine the issues and factors influencing the adoption of ICT specified as critical by each individual. The three interview questions were designed as open-ended questions developed from literature review and were related to the various aspects of factors that affect the adoption of ICT in healthcare organisations.

To analyse the interviews, the tapes were transcribed verbatim to paper by the researcher to ensure that all the information was intact. The researcher carefully read and re-read each transcript (at least five times) to identify the appropriate nodes or themes that would be used for the analysis.

The interviewers posed many issues and questions related to the ICT field. In order to examine the collected data, each theme was individually analysed, and a general conclusion was reached. These data have been summarised at the end of this paper.

\section{Case Description}

For this study, a newly established hospital is defined by hospital founded and established after year 2000 . Conversely, those hospitals founded and established before the year 2000 were classified as experienced and matured hospitals (Table 1 ).

\section{Results and Discussion}

\section{Demographic Distribution of Study Participants}

A total of 37 respondents, comprising 31 (84\%) foreign nationals and six Saudi nationals (16\%), participated in the study.

The educational attainments of the respondents were as follows: $8 \%(N=3)$ were PhD holders, $40 \%(N=15)$ had 
Table 1:

\begin{tabular}{|c|c|c|c|}
\hline Branches & $\begin{array}{l}\text { Operating } \\
\text { year }\end{array}$ & Hospital name & \multirow{4}{*}{ 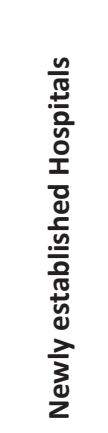 } \\
\hline - & 2000 & $\begin{array}{l}\text { Kingdom } \\
\text { Hospital }\end{array}$ & \\
\hline- & 2001 & $\begin{array}{l}\text { Specialized } \\
\text { Medical Center } \\
\text { Hospital }\end{array}$ & \\
\hline 8 & 2003 & $\begin{array}{l}\text { Sulaiman Al- } \\
\text { Habib Medical } \\
\text { Group }\end{array}$ & \\
\hline 6 & 1975 & $\begin{array}{l}\text { Al-Muwasat } \\
\text { Hospital }\end{array}$ & \multirow{2}{*}{ 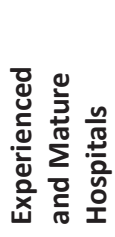 } \\
\hline 6 & 1988 & $\begin{array}{l}\text { Saudi German } \\
\text { Group }\end{array}$ & \\
\hline
\end{tabular}

master's degrees, $45 \%(N=17)$ had bachelor's degree, whereas $5 \%(N=2)$ were diploma holders. The majority of the respondents, with a combined percent of $85 \%$, have either bachelor's or master's degrees. Twenty-four (65\%) respondents were male, whereas 13 (35\%) were female.

\section{Typical sectoral approaches to ICT adoption}

On the basis of the research questions and corresponding responses elicited, the major factors contributing to and acting as barriers to ICT adoption were identified. It was found that the variables tended to facilitate and shape various expectancies.

\section{- $\quad$ Perceived usefulness}

Along with the general external variables that prevail, IT departments appear to perceive ICT as their immediate means of confronting core issues related to, but not limited to, the scope of a planned action, service coverage, data management and security and meeting business demands. Despite differences in emphases by their respective management, IT professionals would look up to ICT as a potential solution for coping with increasing patient demands for quality healthcare, with little regard for sector features. However, the typical clinical setting in the Kingdom of Saudi Arabia (KSA) is still characterised by manual data collection processes. Some examples are admission and discharge activities as well as the writing of prescriptions and clinical reports that are more prevalent in physicians' clinics and nurse stations.

The results of this study suggest that the typical sectoral orientation of a hospital can greatly shape and influence its ICT infrastructural requirements. Following the above discussions, the main sectoral orientation of the hospitals was included in the study (Figure 1).

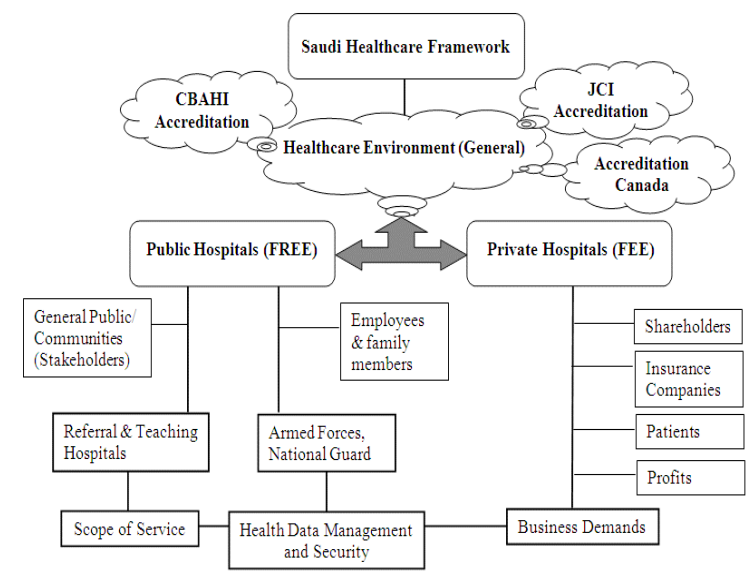

Figure 1: Typical Sectoral Approaches to ICT Adoption

\section{- $\quad$ Framework of UTAUT}

Because this study was undertaken at an institutional level and included IT professionals, a pre-conceived notion that views ICT as a solution was expected. Relative to this notion, the intention to use ICT was already a profound concept or a known approach to the problems referred to IT departments. With regard to the respondents of this study, the use of ICT was almost always indispensable, and in these individuals, behavioural intentions (BIs) to use ICT are already present at the onset of objective-setting or problem-solving.

In the UTAUT model (figure 2), there are four constructs that act as determinants of BIs: (1) performance expectancy (PE), (2) effort expectancy (EE), (3) social influence (SI) and (4) facilitating conditions (FCs).

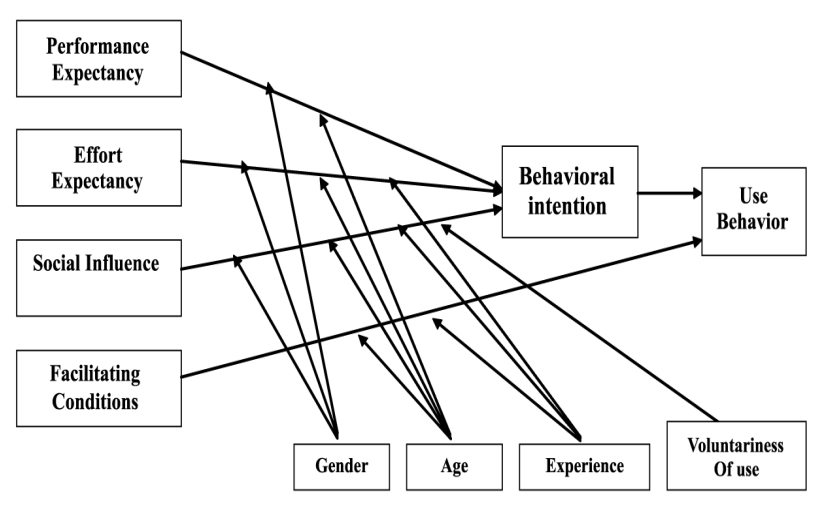

Figure 2: The UTAUT model

Nonetheless, just as UTAUT was originally developed to predict acceptance by non-IT professionals, the use of the UTAUT model by IT professionals yielded a hypothetical framework structured quite differently from the expectations in the original UTAUT context. This study can put forward a proposition suggesting that the four key moderating factors identified in the original UTAUT 
model by ${ }^{11}$ have little to no significance for employed IT professionals compared with that for non-IT professionals. One probable explanation is the homogenous features and work functions of the respondents (i.e. professions, levels of IT literacy and expected job performances under each one's departmental management and organisational culture).

\section{- Derived Analytical Model}

The development of this framework was based on the respondents' narratives The narrative accounts of the respondents indicated that decisions by the higher management, strategic objectives, pacing of IT infrastructure with overall hospital development (organisational functions), funding and release of budget (facilitating factors) and opinions and consensus within the department and across departments (SIs) have shaped their intentions and behaviours in the direction of factors such as which system to use, what to deploy and how to develop it (i.e. in-house or vendor-developed programmes and integration). Therefore, there were three known determinants that have direct influences on BIs: SI, organisational objectives (OOs) and FCs. The two moderating factors external to organisation, namely vendor's credibility (VC) and turnover and talent acquisition (TTA), converge with BIs at the PE and EE points. Instead of $P E$ and EE directly influencing BIs, the latter joins VC and TTA in moderating the impacts of PE and EE, respectively, which consequently influence use behaviour. To illustrate, this can be given as follows: $\mathrm{VC} \rightarrow \mathrm{PE} \rightarrow \mathrm{Bls}$ and TTA $\rightarrow \mathrm{EE}$ $\rightarrow$ Bls.

\section{- Determinants of Behavioural Intentions}

\section{Organisational objectives}

For this study, OOs were defined as the extent or degree to which they influence Bls to recommend and use a projected size or array of ICT infrastructure perceived by IT professionals as necessary to implement and achieve an envisioned objective. Depending on the expanse of the plan, i.e. whether it is long-term or short-term, a corresponding action is presumed to be implemented according to an ICT development scheme that possibly varies from one organisation to another.

Reasonably, IT managers are aware that the fundamental prerequisite for determining the size of ICT, whether it is a new installation or upgrade, is its utilisation, which should match their interim or long-term project needs as closely as possible.

\section{Facilitating conditions}

This study defined FCs as the extent to which an IT professional believes that an organisation renders support to facilitate ICT development and plan implementations. They can be understood as the perceived amount of support that IT professionals receive from the organisation to meet their ICT-related targets.

On the basis of the research questions, three variables were pre-qualified in this study as determinants of ICT adoption. Two pertain to internal (top management support and selection and procurement) variables and one to an external variable (price). Conversely, these may be translated under the model derived from UTAUT as conditions that facilitate ICT use.

\section{- Social Influence}

SI was applied in this study from a social perspective that is much wider than that originally defined in the UTAUT model. Far more than the degree of the user's perception about the significance of beliefs held by other people in terms of using a new technology (11), the context of SI used in the analysis refers by and large to social demands for quality healthcare services, quicker patient turnaround and faster insurance claims processing.

\section{Qualitative Evaluation of Total Bls}

Influence of business demands was a common feature for all five private hospitals involved in this study. Approximately $70 \%$ of the IT professionals interviewed explained how their departments assume the role of reactors according to growth, client demands and patient needs. The results showed that newer and older private hospitals demonstrated different approaches to ICT infrastructure development. One newer and two older hospitals had chosen a vendor-developed approach with built-in software and applications, whereas two newer ones had customised their own systems and software in-house.

\section{A. Social Influence}

With private hospitals, public pressure comes from paying patients and insurance companies that often demand quicker turnaround and faster claims processing. The major involvement of insurance companies as third party places pressure and influence on private hospitals to adopt certain ICT nomenclatures or structures matching third party requirements because of which conformity pressures would often necessitate ICT implementation outside the true healthcare constructs. Other than patients and companies, the top management, including the CEO, the $\mathrm{COO}$ and the like, may also influence the IT department for the use of certain specifications or programs that may not have been innovated or introduced previously by the IT department.

\section{B. Facilitating conditions}

As Sarosa (1) emphasised, the resources provided by the top management, including financial resources, IT infrastructure availability, training support and operational expenses, can altogether encourage ICT adoption in an organisation. Largely, private hospital managements support ICT development with assiduousness over expected outcomes and return of investments. This is particularly observed in the older hospitals, which consider some factors to be more important than ICT, such as medical equipment. Staff training support (i.e. funds for training) is also lacking in privately owned hospital establishments. 


\section{Organisational objectives}

OOs in the private hospital sector are business-driven, with strong indications suggesting that the pace of ICT development is anchored on incumbent or short-term business demands. Conversely, private hospitals may have to wait for the opportunity to develop before they can move on to decide whether investments in ICT would be feasible.

\section{Moderators of Expectancies}

In all five cases included in this study, none of the moderators in the original UTAUT model were considered critically important by IT managers, colleagues or subordinates in the IT profession. Instead, it was evident that managers were more concerned about the effects of VC and TTA on $P E$ and $E E$, respectively. The participants tackled the issue of moderating factors in the context of IT human resource management, where independent variables such as age, gender, experience and voluntariness of use were not considered as factors contributing to adoption constraints. Rather, they were considered more as variables that can be dealt with at human resource levels at preemployment and personnel management (by department heads) during stages of employment. Therefore, every IT professional who is a member of the IT department works under the assumption of competence and performs his/ her role and tasks. If any of these variables (age, gender, voluntariness of use and experience) negatively influence Bls of an individual IT professional, the department heads or immediate supervisors (IT managers) will have to assume their roles to deal with it internally. Besides, IT managers are held partly responsible for the performance of their department or team. Any deficiencies in subordinates, nonetheless, reflect upon the managerial capabilities of the IT managers.

Consequently, on the basis of the perspectives gathered from this study, IT managers have attributed tendencies of moderation to two external moderating factors: VC affecting PE (VC $\rightarrow \mathrm{PE}$ ) and TTF affecting EE (TTF $\rightarrow \mathrm{EE}$ ). Evidently, no internal factor or any moderator originating from within one's department was mentioned. Instead, this study found that PE was linked to VC very tightly, indicating strong dependence on the vendor's capability of sustaining technical support, even for periods longer than the terms originally stipulated in the contract (VC $\rightarrow$ sustained technical support $\rightarrow$ PE). Conversely, PE is mainly anchored to the vendor's reliability, reputation and good service track record, thus leading to the vendor's established credibility (VC = reliability + reputation + good service track record $\rightarrow \mathrm{PE}$ ). Therefore, if $\mathrm{PE}$ is linked to $\mathrm{VC}$, then the degree of confidence as well as factors that contribute to the enhancement of an IT professional's performance in the surveyed hospitals are partly dependent on the vendor capabilities to extend technical support.

Because the VC $\rightarrow$ PE link had become more profoundly identified as a dependent and external variable, another external factor associated to show strong dependence in the hospitals was TTF. In this study, TTF was viewed to be critical to $E E$ (TTF $\rightarrow E E$ ). As with any organisation, when an employee who plays a vital role or responsibility leaves, the vacancy leaves a departing expertise that needs to be filled in a timely and competent manner. If the IT staff is unprepared, the level of ease that other users already have in working with the system will cause adverse adjustments or alterations. Unfortunately, the Saudi labour context and other mandatory policies concerning expatriate labour promote the recurrences of TTF across many sectors and industries.

\section{A. Behavioural Intentions}

While the configuration of the model is a modified version of the original UTAUT, the BI deserves also a modified description. The interview participants have indicated that their roles are often not limited only to system integration or computational program development; they should also deal with knowledge facilitation and skills transfer and development to all the users of IT across all departments. Therefore, Bls should be viewed from the perspective of not only user intentions but also the degree to which an IT professional is influenced by OOs, SI and FCs to take the lead in promoting positive use behaviour upon others.

\section{B. Vendor's Credibility}

This factor, which is external to the organisation, was found to be a critical component to ICT adoption because there were instances in KSA where some vendors abandoned their responsibilities in the midst of unmanageable difficulties (i.e. vendor terminates or breaches service contracts). Furthermore, whenever an expected performance fails, the organisation is at the greatest disadvantage. Several measures have been undertaken to ameliorate this problem, one of which is to seek intervention from the $\mathrm{MOH}$ or the Ministry of Commerce and Industry to blacklist erring contractors and vendors.

Vendor integrity is an important aspect while choosing a system. Numerous studies (9-11) provide evidence that sellers and buyers of IT systems can develop relationships before any sale, which in turn influence purchasing decisions at a later period.

\section{Turnover and Talent Acquisition}

In the same context as 'being around when computing efforts by others run tough', an IT personnel is expected to ease the adoption process by helping others manage through and get acquainted with the system. With a positive $\mathrm{BI}$, the perception of difficulties will be diffused and efforts expectancy will be relatively eased. However, the labour structure in KSA can be a disincentive to effective EE promotion because of quick talent turnover and subsequent difficulty in acquiring an equally competent individual to replace a departing employee.

\section{Lack of management support to provide training}

The notion of temporary employment is a disincentive for hospital management to offer and invest in extensive 
training programmes for foreign employees. Because the ratio of long-term employment is negligible, managements tend to withhold offers for advancements knowing that many of those who will receive training will leave shortly, and the original sponsors may no longer benefit over a longer term.

Assumingly, when a system switches users (from the previously trained user to a novice), certain performance expectations would be likewise affected by the emergence of gaps such as the relative lack of awareness by the new user. On the basis of the UTAUT model, awareness deficiencies delimit PE and breed negative perceptions towards the system from new users, thus forming barriers to ICT adoption.

\section{Shortage of IT professionals}

This is another challenge brought about by the nonpermanence of foreign labour and shortages of domestic or local IT talents. This study has found that Saudi IT professionals employed in the private sector prefer to work in the public sector because it provides job security and high pay. Workers are always eager to catch that opportunity when made available (16).

\section{Conclusions and Recommendations}

The use of ICT across the health value chain is widely recognised to be of significant importance for lowering costs and improving services at all care levels in the entire KSA (3). The major institutions mandated by the KSA Government, namely $\mathrm{MOH}$, the Communications and Information Technology Commission, the King Abdul-Aziz University (KAU) and the Central Board for Accreditation of Health Care Institution (CBAHI), have assumed their respective invaluable roles in promoting the use of ICT products and services for improving healthcare delivery.

However, the functional roles of these institutions remain limited to central roles in spearheading initiatives or disseminating good practices that do not generally carry a mandate to control, restrict or regulate ICT practices in healthcare facilities. Therefore, all healthcare facilities are exposed to identical sets of external factors, whereby the concept of autonomy or self-regulation in terms of ICT adoption still remains the standard guiding parameter. However, internal deficiencies to control lapses are noticeable, including poor data delivery, time lags, weak or inferior applications, overestimations and underutilisation.

Having applied the UTAUT model in departmental or collective contexts, the eventual outcome necessitated the modifications in the UTAUT configuration. The newly identified categories influencing Bls were found to be consistent and applicable to all hospital sectors even if specific definitions relevant to the meaning of each category are assigned. Although more research is needed, it appears that some viable solutions can be offered, or perhaps, some positive outcomes can be expected if BIs of IT professionals profoundly support their OOs and are supported by the organisations they serve. Lastly, the inclusion of Bls as an active interactive moderator of use behaviour presents an encouraging tone towards the potentials of cushioning negative impacts and relieving ICT professional users of the dilemma brought about by unreliable vendors and quick employee turnovers.

\section{References}

1. Barnesa S, Vidgenb R. Data triangulation and web quality metrics: A case study in e-government. Information \& Management. 2006; 43(6): 767-777.

2. Higgins T, Crosson J, Peikes D, McNellis R, Genevro J, Meyers D. Using Health Information Technology to Support Quality Improvement in Primary Care: Agency for Healthcare Research and Quality. 2015.

3. Sidorova A, Torres R, Al Beayeyz A. The Role of Information Technology in Business Process Management.: Springer Berlin Heidelberg. 2015.

4. Chattopadhyay S. A framework for studying perceptions of rural healthcare staff and basic ICT support for e-health use: an Indian experience. Telemedicine and e-Health. 2010; 16(1): 80-88.

5. Sarantok K. Evaluating nursing documentation research designs and methods: systematic review. J Adv Nurs. 2009; 2(65): 464-476.

6. CITC. Communications and Information Technology Commission Publication. 2015.

7. Altuwaijiri M. Electronic-health in Saudi Arabia. Just around the corner. Saudi Medical Journal. 2008; 29 (2): 171-178.

8. Ajzen I, Fishbein M. Understanding attitudes and predicting social behaviour. Englewood Cliffs, NJ: Prentice-Hall. 1980.

9. Ajzen I, Driver B. Prediction of leisure participation from behavioural, normative, and control beliefs: An application of the theory of planned behaviour. Leisure Sciences. 1991; 13(3): 185-204.

10. Rogers M. Diffusion of Innovations (Fourth Edition). New York, Free Press. 1995.

11. Venkatesh V. User acceptance of information technology: Toward a unified view. MIS Quarterly. 2003; 27(3): 425-478.

12. Schaper LK, Pervan GP. Ict and ots:A model of information and communication technology acceptance and utilisation by occupational therapists. Int J Med Inform 2007; 76s: S212-S221.

13. Huskey P. Adoption of Healthcare Information Technology. Castle Point on Hudson Hoboken, NJ: School of Technology Management. 2009.

14. Ivanov D. Ensuring long-term adoption of technology: Mandated use and individual habit as factors that 
establish technology into healthcare practice. Care Western Reserve University. 2008.

15. Hamidfar $M$, Limayem $M$, Hessameddin S. Using the UTAUT Model to Explore Iranian Physicians and Nurses' Intention to Adopt Electronic Patient Records. Paper presented at: International Conference on
E-Learning, E-Business, Enterprise Information Systems, and E-Government. 2008.

16. John F. Helliwell, Richard Layard, Sachs J. world happiness report 2015: Sustainable Development Solutions Network. 2015. 
